\title{
Prevalence and Factors Associated with Hydatidiform Mole among Patients with Missed Abortion
}

\author{
Dr. Trifa Yousif Mutalib
}

Department of Obstetrics and Gynecology, maternity teaching hospital Kurdistan Region, Erbil City, Iraq.

Received: 25 Nov 2021; Received in revised form: 03 Jan 2022; Accepted: 12 Jan 2022

C 2022 The Author(s). Published by TheShillonga. This is an open access article under the CC BY license (https://creativecommons.org/licenses/by/4.0/)

\begin{abstract}
A large number of studies have reported different prevalence rates for hydatidiform mole in different regions, making it difficult to determine the exact prevalence of this condition. There has been no previous study that has determined the prevalence of $H M$ and the risk factors associated with it among patients who have had an missed abortion and were evacuated from the Medical Center and private hospitals in Erbil. Between August 2015 and October 2021, a total of 180 patients who had undergone amissed abortion were enrolled.. Participation in this study was voluntary and included one hundred and eighty patients with missed abortions who were scheduled for uterine evacuation. The prevalence of HM was 12.8 percent in the overall population. The vast majority of patients with HM (27.5 percent) were under the age of twenty-one years. Risk factors such as parity, contraceptive use, previous abortion, and blood group were not found to have a statistically significant association with the outcome. Prevalence of HM among patients with missed abortion was high (12.8 percent), with age between 15-20 years being the only significant risk factor associated with the presence of HM among those who had anmissed abortion. As a result, we recommend that evacuated products of conception be submitted for histopathological analysis in order to reduce the number of missed opportunities.
\end{abstract}

Keywords_Prevalence, hydatidiform mole, missed abortion, Erbil, Kurdistan Region of Iraq.

\section{INTRODUCTION}

To describe abnormal gestations that arise from the villous trophoblast associated with pregnancy, the term hydatidiform mole (HM) is used. Partial hydatidiform mole (PHM) is one of two histological types of HM: the other is the complete hydatiform mole (Usui et al., 2020). Other trophoblastic tumors that can occur during pregnancy include choriocarcinoma and interstitial trophoblastic tumors, which arise from villous trophoblast and interstitial trophoblast, respectively (Memtsa et al., 2020).

Different regions around the world have varying levels of prevalence of HM. According to research done in developed countries, the prevalence of high-risk pregnancy (HM) is between 0.5 and 1.1 per 1000 pregnancies, whereas the higher prevalence is 2 per 1000 pregnancies (Khooei et al., 2019). Many countries have different ranges, for example Middle east countries have $2.2 \%$ prevalence of HM, South Africa has a $1.2 \%$ prevalence per 1000 births, and Nnewi, As a result of these findings (Nguyen et al., 2018), it's possible that HM is more common than previously thought in some countries (Li et al., 2021). Lack of research into this issue means that the prevalence of HM in Iraq's Kurdistan region is unknown (Jauniaux et al., 2020). The most well- known risk factors for HM are maternal age and previous molar pregnancies (Lund et al., 2020). For example, women over the age of 40 have a three-fold increased risk of a complete mole, while patients with a history of molar pregnancy have a much higher risk (Yamamoto et al., 2021). Abortion and HM appear to be linked in a number of studies (Sato et al., 2019). Fallahi et al., (2019), found that of the 93 women studied, nine had HM, which is consistent with previous studies. According to another study by Horn et al., CHM was found to be responsible for $5.1 \%$ of spontaneous abortions in placenta tissue (Usui et al., 2018).

In patients who have had an abortion, initial clinical findings rarely point to HM as a possibility (Mulisya et al., 2018). Often, we do not perform routine histopathological analysis on the evacuated products of conception. It's possible that patients with HM will be mismanaged if this condition isn't recognized as the root of the miscarriage. To determine the prevalence and associated risk factors of HM in the Erbil City, Kurdistan region of Iraq, this study was conducted. 


\section{MATERIALS AND METHODS}

Three private hospitals in Erbil City participated in this cross-sectional study. During the period of August, 2015, and October, 2021, gynecological wards admitted patients for missed abortions. Using the Kish and Lesley formula, we were able to meet the minimum sample size of 180 women who had missed abortion. Termination of pregnancy done by medical or surgical ways and products of conception sent for histopathological study .

\section{Data collection}

The women who agreed to take part in the study filled out a detailed questionnaire about their demographics, their pregnancies, and their postpartum experiences. Formalin $10 \%$ was used to preserve the fetuses of 180 participants who had been evacuated from the study..

\section{Data analysis}

According to the pre-codes, data was entered into Microsoft Office Excel 2010 and analyzed using STATA version 11. Socio-demographic and maternal characteristics were studied using descriptive statistics. A proportion or percentage was used for categorical variables, and a mean was used for continuous variables (standard deviation). The chi-square statistical test was used to examine the relationship between HM and categorical variables. Bivariate logistic regression took into account only variables with a p-value less than or equal to 0.05 . The odds ratio was used to estimate the degree of association and a $95 \%$ confidence interval was provided. This study had a $5 \%$ level of statistical significance, so $\mathrm{p}$ values less than 0.05 were considered significant.

\section{RESULTS}

Patients who agreed to participate in this study were only eligible for participation in the study if they met the following criteria: There was a 26.9-year-old average age of participants. Around a quarter of the participants (42 percent) were housewives, and the majority of them $(78.3 \%)$ were self-referred from their own homes. Most patients $(67.7 \%)$ had at least a high school diploma, and only about $9 \%$ of those who took part in the study reported having a job (Table 1$)$.

Table.1: Social demographic characteristics of the study population

\begin{tabular}{|c|c|c|}
\hline Characteristics & $\mathrm{n}$ & $(\%)$ \\
\hline \multicolumn{3}{|l|}{ Admission status } \\
\hline Self referral & 141 & 78.3 \\
\hline Referred & 39 & 21.7 \\
\hline \multicolumn{3}{|l|}{ Occupation } \\
\hline House wife & 75 & 41.7 \\
\hline Student & 27 & 15.0 \\
\hline Employee & 16 & 8.9 \\
\hline Businesswoman & 62 & 34.4 \\
\hline \multicolumn{3}{|c|}{ Level of education } \\
\hline None & 8 & 4.4 \\
\hline Primary & 122 & 67.8 \\
\hline Secondary & 48 & 26.7 \\
\hline Post secondary & 2 & 1.1 \\
\hline \multicolumn{3}{|l|}{ Marital status } \\
\hline Single & 21 & 11.7 \\
\hline Married & 140 & 77.8 \\
\hline Cohabiting & 17 & 9.4 \\
\hline separated & 2 & 1.1 \\
\hline
\end{tabular}


There was a $12.8 \%$ overall prevalence of HM (23/180). 11.1 percent (20/180) of patients with missed abortions had complete hydatidiform mole (CHM). Prev- and 1.7 percent
(3/180) of the participants had a normal placenta tissue, while the remainder had a partial hydatidiform mole (PHM) (Figure 1).

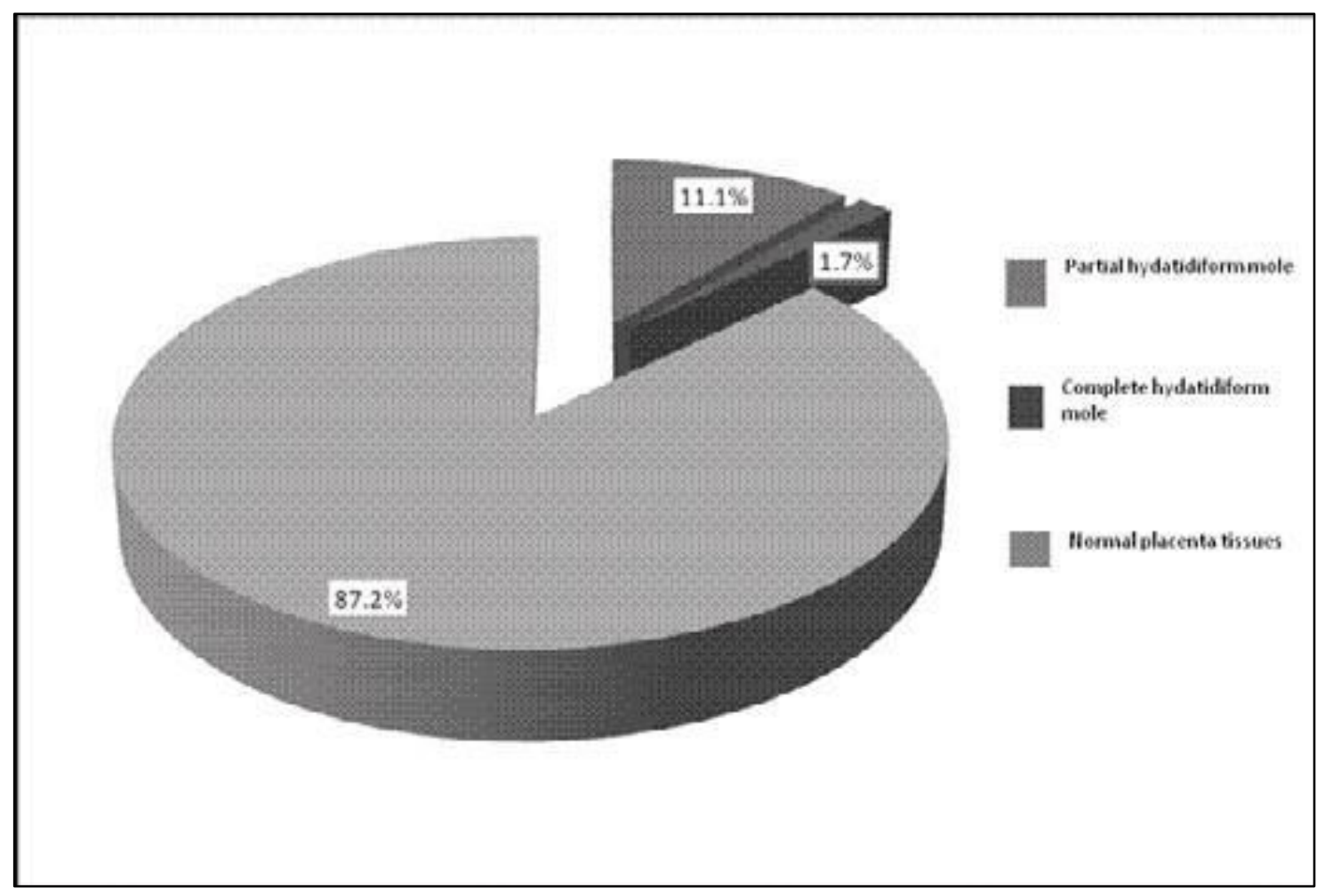

Fig.1: The prevalence of HM and its pattern

As it can be seen in figure (1), 27.5 percent of the population between the ages of 15 and 20 was found to have HM, with 20 percent having PHM and 7 percent having CHM, which was statistically significant $(\mathrm{p}=0.01)$.

Prevalence of HM was found to be higher in the primiparous group $(15.8 \%)$ than in the multiparous group $(9.7 \%)$, but HM was not found among the grand multiparous (56.1\%). Although the association between parity and HM was not statistically significant $(\mathrm{p}=0.29), 13$ of the primiparous women had a PHM and three had CHM.

Smoking has been linked to an increased risk of HM. Only 23 of the patients in this study admitted to ever having smoked a cigarette. The prevalence of HM in this group was 21.7 percent $(5 / 23)$ compared to 11.5 percent $(18 / 157)$ among those who had never smoked. Cigarette smoking quantity and duration could not be elicited. Eighty-five of the participants $(47.2 \%)$ had ever used contraception. 12.6 percent of those who had never used contraception tested positive for HM, compared to 12.9 percent of those who had. PHMs and CHMs were found in $9.5 \%$ and $3.2 \%$ of participants with no prior history of contraceptive use, respectively. There was, however, no statistically significant link $(\mathrm{p}=0.95)$ between HM and a history of contraceptive use.

One in every thirteen (14\%) participants had a history of HM, compared to 117 (65\%), who had never had an abortion before but had one in every thirteen (12\%) of the participants in the study who had. A total of 5 of the 63 participants who had previously had an abortion had an induced abortion, while the remaining 58 had a spontaneous abortion. When it comes to spontaneous abortion, nine (15.5\%) of the participants had HM, while none of the participants who had induced abortions had the condition. This study, however, found no link between HM and a prior history of abortion $(\mathrm{p}=0.66)$. None of the participants had previously been diagnosed with HM. 
Table 2: Prevalence of HM by maternal characteristics for participants at Private hospitals

\begin{tabular}{|c|c|c|c|c|c|c|}
\hline Variables & $\mathrm{n} \%$ & Normal & tissue $\%$ & OR & $95 \% \mathrm{CI}$ & P value \\
\hline \multicolumn{7}{|l|}{ Parity } \\
\hline Primiparous & $101(56.1)$ & $85(84.2)$ & $16(15.8)$ & 1 & - & 0.29 \\
\hline Multiparous & $72(40)$ & $65(90.3)$ & $7(9.7)$ & 0.570 & $0.2-1.5$ & \\
\hline Grandimultiparous & $7(3.9)$ & $7(100)$ & $0(0.00)$ & - & - & \\
\hline \multicolumn{7}{|l|}{ Cigarette smoking } \\
\hline Yes & $23(12.8)$ & $18(78.3)$ & $5(21.7)$ & 1 & - & 0.17 \\
\hline No & $157(87.2)$ & $139(88.5)$ & $18(11.5)$ & 0.466 & $0.15-1.4$ & \\
\hline \multicolumn{7}{|l|}{ Contraceptive use } \\
\hline Yes & $85(47.2)$ & $74(87.1)$ & $11(12.9)$ & 1 & - & 0.95 \\
\hline No & $95(52.8)$ & $83(87.4)$ & $12(12.6)$ & 0.951 & $0.4-2.3$ & \\
\hline $\begin{array}{l}\text { Previous abortion } \\
\text { Yes } \\
\text { Induced } \\
\text { Spontaneous No }\end{array}$ & $\begin{array}{l}63(35) \\
5(7.9) \\
58(92.1) \\
117(65)\end{array}$ & $\begin{array}{l}54(85.7) \\
5(100) \\
49(15.5) \\
103(88.0)\end{array}$ & $\begin{array}{l}9(14.3) \\
0(0.0) \\
9(15.5) 14 \\
(12)\end{array}$ & $\begin{array}{l}1 \\
0.816\end{array}$ & $\begin{array}{c}- \\
0.3-2.0\end{array}$ & 0.66 \\
\hline $\begin{array}{l}\text { Previous history of HM } \\
\text { Yes }\end{array}$ & $0(0.0)$ & $0(0.0)$ & $0(0.0)$ & - & - & \\
\hline No & $180(100)$ & $157(87.2)$ & $23(12.8)$ & 1 & - & \\
\hline \multicolumn{7}{|l|}{ Blood group $(\mathrm{Rh}+\mathrm{ve})$} \\
\hline A & $35(19.4)$ & $28(80)$ & $7(20)$ & 1 & $-0.1-1.4$ & 0 \\
\hline B & $40(22.2)$ & $37(92.5)$ & $3(7.5)$ & 0.32 & $0.01-1.15$ & . \\
\hline $\mathrm{AB}$ & $31(17.2)$ & $30(96.8)$ & $1(3.2)$ & 0.13 & $0.3-2.2$ & 1 \\
\hline $\mathrm{O}$ & $74(41.2)$ & $62(83.8)$ & $12(16.2)$ & 1 & & \\
\hline
\end{tabular}

According to table (2), 74 (41.2 percent) of the participants had blood group 'O', with 12 (16.2 percent) of those having HM. There were 7 (20\%) of the 35 participants with blood group 'A' who had HM, followed by $3(7.5 \%)$ of the participants with blood group 'B'. A p-value of 0.1 was found to be statistically insignificant between HM and blood group (Table 2).

\section{DISCUSSION}

According to the results of this study, 12.8 percent of the participants had HM, which was in line with a previous study in Mexico. However, the prevalence of HM in this study was higher than previously reported prevalence of HM that ranged between 0.3 percent and 3.4 percent in other countries. Most of these studies were retrospective, and their sample population included only patients with gestational trophoblastic diseases, which could account for the discrepancy in results (Buza et al., 2019).

There was a 3.42 percent prevalence of CHM, which is higher than our own set- ting's rate of 3.36 percent. The difference could be explained by the fact that the prospective study included patients who had been diagnosed with CHM both clinically and histologically.

There was a strong correlation between the prevalence of $\mathrm{HM}$ and maternal age at the lower end of the normal range in this study ( $\mathrm{p}=0.01$ ). This was in line with other studies' findings. According to previous research, risk increases with age, but this study found no evidence to support that theory. This could be because in our community, the majority of women reach menopause at around the age of 50. Further research involving a larger group of patients is needed to establish a definitive link between HM and an advanced maternal age, as these conflicting findings show. 
According to the results of this study, the majority of participants with HM were singletons (15.8 percent ). In addition, PHM (13.9\%), rather than CHM (11.9\%), was the most common (3 percent). There was a statistically insignificant decrease in the risk of HM with an increase in the number of births. In Italy, Parazzini et al. found a similar result, but they only found a trend in risk for PHM. Kumar et al. reported that the risk of HM increased with parity19, but the current findings differ from their findings. In the other studies, the majority of multiparous patients were over 40 years old, which is also reported to be a risk for HM, which could explain the discrepancy.

This study found that 12.9 percent of participants with a history of contraceptive use were found to have HM (Table 2). This study's findings, despite their small size (47.2 percent), are consistent with those previously reported by a study in the United States. It's possible that the lack of an association between $\mathrm{HM}$ and prior contraceptive use $(p=0.95)$ is due to the fact that a sizable percentage of participants in this study who were diagnosed with HM had no prior history of contraceptive use. Because Palmer et al used a multicenter case control study to establish the link between contraceptive use and HM (Xing et al., 2021).

More than a third (35\%) of the participants in this study had a history of previous abortions, including 14.3 percent of those who had HM. These findings are in line with those of Parazzini et al, who found that women with a history of prior abortion are more likely to experience HM. An Italian study found that spontaneous abortion was more closely linked to HM than induced abortion. 15.5 percent of participants with spontaneous abortions were diagnosed with HM, while none of the participants who had an induced abortion were diagnosed with this condition (Cozette et al., 2020).

In this study, there was no previous history of HM among the participants. Since it is not standard practice in our settings to routinely histologically analyze every retained product of conception (RPOC) obtained after evacuation, the possibility of previous HM had to be considered. As a result, it is possible that some of the 35 percent of participants with a history of abortion, 14.3 percent of whom had HM, may have previously had HM in an abortion.

A blood group 'A' participant was found to have $20 \%$ of $\mathrm{HM}$ in this study. According to blood groups, this was the most $\mathrm{HM}$ in the population. The results of this study contradict the findings of Lorigan et al, who found that blood group 'B' was the most common in cases of HM. Because the study population and other risk factors for HM were not evenly distributed based on blood group, it is inconclusive to say that participants with blood group 'A' are at an increased risk.

\section{CONCLUSION}

Prevalence of HM among patients with missed abortion was high (12.8 percent), with age between 15-20 years being the only significant risk factor associated with the presence of HM among those who had anmissed abortion. As a result, we recommend that evacuated products of conception be submitted for histopathological analysis in order to reduce the number of missed opportunities.

\section{REFERENCES}

[1] Aguinaga, M., Rezaei, M., Monroy, I., Mechtouf, N., Pérez, J., Moreno, E., ... \& Slim, R. (2021). The genetics of recurrent hydatidiform moles in Mexico: further evidence of a strong founder effect for one mutation in NLRP7 and its widespread. Journal of Assisted Reproduction and Genetics, $1-8$.

[2] Aiob, A., Naskovica, K., Sharon, A., \& Bornstein, J. (2021). A possible association between hydatidiform mole and the COVID-19 pandemic: A retrospective cohort study. Gynecologic Oncology, 161(2), 454-457.

[3] Anguiano, A., Wang, B. T., Lammers, K. Y., Mahon, L. W., Truitt, N., Dohany, L., \& Boyar, F. Z. (2020). Single Nucleotide Polymorphism-Based Chromosomal Microarray Evaluation of Hydatidiform Moles: A US National Reference Laboratory Experience. Open Journal of Obstetrics and Gynecology, 10(8), 1122-1134.

[4] Buza, N., McGregor, S. M., Barroilhet, L., Zheng, X., \& Hui, P. (2019). Paternal uniparental isodisomy of tyrosine hydroxylase locus at chromosome $11 \mathrm{p} 15$. 4: spectrum of phenotypical presentations simulating hydatidiform moles. Modern Pathology, 32(8), 1180-1188.

[5] Cozette, C., Scheffler, F., Lombart, M., Massardier, J., Bolze, P. A., Hajri, T., ... \& Cabry, R. (2020). Pregnancy after oocyte donation in a patient with NLRP7 gene mutations and recurrent molar hydatidiform pregnancies. Journal of Assisted Reproduction and Genetics, 37(9), 2273-2277.

[6] Fallahi, J., Razban, V., Momtahan, M., Akbarzadeh-Jahromi, M., Namavar-Jahromi, B., Anvar, Z., \& Fardaei, M. (2019). A novel mutation in NLRP7 related to recurrent hydatidiform mole and reproductive failure. International journal of fertility \& sterility, 13(2), 135.

[7] Hemida, R., van Doorn, H., \& Fisher, R. (2020). A Novel Genetic Mutation in an Egyptian Patient with Recurrent Biparental Complete Hydatidiform Mole. Studies on Gestational Trophoblastic Disease, with Emphasis on Improving Care in Egypt, and Second Curettage in Low Risk Gestational Trophoblastic Neoplasia., 26, 98.

[8] Jauniaux, E., Memtsa, M., Johns, J., Ross, J. A., Sebire, N. J., \& Jurkovic, D. (2020). Ultrasound diagnosis of complete and partial hydatidiform moles in early pregnancy failure: An inter-observer study. Placenta, 97, 65-67. 
[9] Ji, M., Shi, X., Xiang, Y., Cui, Q., \& Zhao, J. (2019). NLRP7 and KHDC3L variants in Chinese patients with recurrent hydatidiform moles. Japanese journal of clinical oncology, 49(7), 620-627.

[10] Khawajkie, Y., Mechtouf, N., Nguyen, N. M. P., Rahimi, K., Breguet, M., Arseneau, J., ... \& Slim, R. (2020). Comprehensive analysis of 204 sporadic hydatidiform moles: revisiting risk factors and their correlations with the molar genotypes. Modern Pathology, 33(5), 880-892.

[11] Khooei, A., Pasdar, F. A., Fazel, A., Mahmoudi, M., Nikravesh, M. R., \& Shahbazian, S. D. (2019). Expression of Pro-Apoptotic Bax and Anti-Apoptotic Bcl-2 Proteins in Hydatidiform Moles and Placentas With Hydropic Changes. Acta Medica Iranica, 27-32.

[12] Lama, P., \& Pariyar, J. (2021). Histological analysis of the products of conception in first trimester spontaneous abortions. Nepal Journal of Obstetrics and Gynaecology, 16(1).

[13] Li, M. W., Li, F., Cheng, J., Wang, F., \& Zhou, P. (2021). Recurrent Androgenetic Complete Hydatidiform Moles with p57KIP2-Positive in a Chinese Family. Reproductive Sciences, 1-7.

[14] Li, P. C., Chang, K. H., \& Ding, D. C. (2021). Incomplete abortion with elevated beta-human chorionic gonadotropin levels mimicking a molar pregnancy: A case report. Medicine: Case Reports and Study Protocols, 2(9), e0134.

[15] Löb, S., Vattai, A., Kuhn, C., Schmoeckel, E., Mahner, S., Wöckel, A., ... \& Vilsmaier, T. (2020). Spliceosome protein EFTUD2 is upregulated in the trophoblast of spontaneous miscarriage and hydatidiform mole. Journal of Reproductive Immunology, 140, 103149.

[16] Lund, H., Vyberg, M., Eriksen, H. H., Grove, A., Jensen, A. Ø., \& Sunde, L. (2020). Decreasing incidence of registered hydatidiform moles in Denmark 1999-2014. Scientific reports, 10(1), 1-10.

[17] Memtsa, M., Johns, J., Jurkovic, D., Ross, J. A., Sebire, N. J., \& Jauniaux, E. (2020). Diagnosis and outcome of hydatidiform moles in missed-miscarriage: a cohort-study, systematic review and meta-analysis. European Journal of Obstetrics \& Gynecology and Reproductive Biology, 253, 206-212.

[18] Moein-Vaziri, N., Fallahi, J., Namavar-Jahromi, B., Fardaei, M., Momtahan, M., \& Anvar, Z. (2018). Clinical and geneticepigenetic aspects of recurrent hydatidiform mole: a review of literature. Taiwanese Journal of Obstetrics and Gynecology, 57(1), 1-6.

[19] Mulisya, O., Roberts, D. J., Sengupta, E. S., Agaba, E., Laffita, D., Tobias, T., ... \& Mugisha, J. (2018). Prevalence and factors associated with hydatidiform mole among patients undergoing uterine evacuation at mbarara regional referral hospital. Obstetrics and gynecology international, 2018.

[20] Nguyen, N. M. P., Ge, Z. J., Reddy, R., Fahiminiya, S., Sauthier, P., Bagga, R., ... \& Slim, R. (2018). Causative mutations and mechanism of androgenetic hydatidiform moles. The American Journal of Human Genetics, 103(5), 740-751.
[21] Nguyen, N. M. P., Khawajkie, Y., Mechtouf, N., Rezaei, M., Breguet, M., Kurvinen, E., ... \& Slim, R. (2018). The genetics of recurrent hydatidiform moles: new insights and lessons from a comprehensive analysis of 113 patients. Modern Pathology, 31(7), 1116-1130.

[22] Patil, B. U., Gangane, N. M., \& Shivkumar, V. B. (2020). The frequency of hydatidiform mole in a tertiary care hospital from central India. Indian Journal of Pathology and Oncology, 7(1), 71-75.

[23] Ronnett, B. M. (2019). Hydatidiform moles: differential diagnosis, diagnostic reproducibility, genetics and ancillary techniques to refine diagnosis. Diagnostic Histopathology, 25(2), 35-52.

[24] Sato, A., Usui, H., \& Shozu, M. (2019). Comparison between vacuum aspiration and forceps plus blunt curettage for the evacuation of complete hydatidiform moles. Taiwanese Journal of Obstetrics and Gynecology, 58(5), 650-655.

[25] Usui, H., Qu, J., Sato, A., Pan, Z., Mitsuhashi, A., Matsui, H., \& Shozu, M. (2018). Gestational trophoblastic neoplasia from genetically confirmed hydatidiform moles: prospective observational cohort study. International Journal of Gynecologic Cancer, 28(9).

[26] Usui, H., Sato, A., Ota, M., Ikeda, J. I., \& Shozu, M. (2020). Androgenetic complete hydatidiform moles with p57KIP2positive immunostaining. American Journal of Clinical Pathology, 154(6), 776-783.

[27] Wang, J., Chen, S. W., Qin, X. Y., Zheng, X. Z., Wang, P., \& Cai, X. Y. (2020). Clinical application of short tandem repeat polymorphism analysis in the differential diagnosis of early hydatidiform mole and hydropic abortion. Clinical and Experimental Obstetrics \& Gynecology, 47(4), 490-495.

[28] Winata, I. G. S., Kusuardiyanto, P., Aryana, M. B. D., \& Mulyana, R. (2021). Cervical Hydatidiform Moles Pregnancy: Diagnosis and Treatment. Open Access Macedonian Journal of Medical Sciences, 9(C), 291-296.

[29] Xing, D., Adams, E., Huang, J., \& Ronnett, B. M. (2021). Refined diagnosis of hydatidiform moles with p57 immunohistochemistry and molecular genotyping: updated analysis of a prospective series of 2217 cases. Modern Pathology, 34(5), 961-982.

[30] Xing, D., Miller, K., Beierl, K., \& Ronnett, B. M. (2022). Loss of p57 Expression in Conceptions Other Than Complete Hydatidiform Mole: A Case Series With Emphasis on the Etiology, Genetics, and Clinical Significance. The American Journal of Surgical Pathology, 46(1), 18-32.

[31] Yamamoto, E., Kanal, K., Soeung, S. C., Fujita, N., Krang, S., Long-Hay, P., ... \& Hamajima, N. (2021). The current situation of health services for hydatidiform mole in Cambodia. Journal of Obstetrics and Gynaecology Research, 47(10), 3652-3660. 